\title{
EDITORIAL
}

\section{Where are lithium carbonate, typical antipsychotics, imipramine, and some other efficacious medications?}

\author{
Antonio E. Nardi, ${ }^{1}$ (iD Antonio G. da Silva, ${ }^{2,3,4}$ (iD Valentim Gentil Filho ${ }^{5}$ (iD \\ ${ }^{1}$ Instituto de Psiquiatria (IPUB), Faculdade de Medicina, Universidade Federal do Rio de Janeiro (UFRJ), Rio de Janeiro, RJ, Brazil. \\ ${ }^{2}$ Faculdade de Medicina, Universidade do Porto, Porto, Portugal. ${ }^{3}$ Associação Brasileira de Psiquiatria (ABP), Rio de Janeiro, RJ, Brazil. \\ ${ }^{4}$ Asociación Psiquiátrica de América Latina (APAL), Brasília, DF, Brazil. ${ }^{5}$ Departamento de Psiquiatria, Faculdade de Medicina, Universidade \\ de São Paulo (USP), São Paulo, SP, Brazil.
}

Efficacious pharmacotherapy changed psychiatric treatment outcomes in the 20th century, fostering a clear revolution in psychiatric care and helping us understand the mind-brain enigma. Among the early new drugs, lithium carbonate, chlorpromazine, imipramine, and tranylcypromine deserve special mention.

Lithium has a long history in medicine since the 19th century. The rediscovery of the effects of lithium on mood disorders began in 1949 in Australia, when John Cade hypothesized that a condition involving uric acid might have some relation to "psychotic excitement." Patients in manic states responded remarkably well, becoming asymptomatic and capable of discharge after years of hospitalization. The breakthrough in the treatment of mania and the prevention of relapse of manic-depressive illness (now known as bipolar disorder) was further established by Schou et al., who carried out a series of randomized controlled trials which raised interest in lithium treatment. ${ }^{2}$ Today, various other drugs are prescribed as mood stabilizers but, despite attempts to underplay its effectiveness, lithium stands alone as the most efficacious one.

In 1945, Häfliger \& Schinder synthesized G22355 (imipramine). ${ }^{3}$ Since its chemical structure was similar to that of chlorpromazine, it was tested for antipsychotic properties, but was ineffective in schizophrenia. However, imipramine had unexpected antidepressant properties: among patients with different psychiatric disorders, those with severe depression and psychomotor retardation experienced remarkable improvement after several weeks of daily treatment with imipramine, the first tricyclic antidepressant (TCA). ${ }^{4}$ In 1957, Kline et al. reported the efficacy of iproniazid in depressive patients. ${ }^{5,6}$ However, the drug proved unsafe, and was eventually substituted by phenelzine and tranylcypromine (only the latter remains available in Brazil). By 1958, more than 400 thousand patients had already been treated with antidepressants. ${ }^{6}$ Again, although dozens of antidepressants were marketed over the next 60 years, none proved more efficacious than imipramine for severe depression or the monoamine

Correspondence: Antonio Egidio Nardi, Laboratório de Pânico e Respiração, Instituto de Psiquiatria, Universidade Federal do Rio de Janeiro, R. Visconde de Pirajá, 407/702, CEP 22410-003, Rio de Janeiro, RJ, Brazil.

E-mail: antonioenardi@gmail.com

Submitted Apr 02 2020, accepted Apr 02 2020, Epub Apr 172020. oxidase inhibitors (MAOls) for atypical and bipolar depressions.

The potential use of chlorpromazine as an antipsychotic drug was suggested by the surgeon Henri Laborit and confirmed by Delay \& Deniker in $1952 .{ }^{7}$ In most patients, chlorpromazine alone in small daily doses $(75 \mathrm{mg})$ was able to control psychotic behavior. Six publications by Delay \& Deniker set the stage for the introduction of chlorpromazine in psychiatry. ${ }^{8,9}$ The antipsychotic effects of phenothiazines and other typical antipsychotics (e.g., the butyrophenones) remain unsurpassed to date. Clozapine is a phenothiazine.

The search for higher efficacy failed, and the reduction in untoward effects of some new drugs was in fact marred by reduced efficacy. The newer drugs have, at best, nearly equal efficacy, with different profiles of action (which is useful, given the variable clinical demands), and different side effects (not always an improvement over their predecessors). The reasons for this lack of more efficacious and safer medications are well known, and duly acknowledged by pharmacologists and independent clinical investigators: all psychopharmaceuticals were discovered by chance or serendipity, and we do not really know their underlying mechanisms of action or the actual pathophysiology of the disorders (or diseases) that we wish to treat. The fact remains that they help a number of patients better than placebo, and deserved their marketing authorizations. But they are not strictly better, or more "modern," as often marketed. And they are more expensive.

To sum up, despite billions of dollars invested in the development and marketing of newer antipsychotics, antidepressants, and mood stabilizers over the past seven decades, no new drug is more efficacious than older ones. ${ }^{9-11}$ The TCAs, the MAOIs, the "typical" antipsychotics, and lithium remain the most effective substances for severe mood, psychotic, and some neuropsychiatric disorders. ${ }^{9-11}$ In fact, lithium carbonate has repeatedly proven the most effective agent for the prevention of relapses of bipolar disorder, suicide, and several other

How to cite this article: Nardi $A E$, da Silva AG, Gentil Filho V. Where are lithium carbonate, typical antipsychotics, imipramine, and some other efficacious medications? Braz J Psychiatry. 2021;43: 2-3. http://dx.doi.org/10.1590/1516-4446-2020-1007 
psychiatric conditions, such as explosive aggressive behavior. $^{10}$

Due to commercial interests, rather than to differences in efficacy or effectiveness, most psychopharmaceuticals have had short lives on the global market. Some have resisted, despite lost patent rights and attempts to play down their effectiveness vis à vis the newer drugs, mostly thanks to the so-called "test of time" (showing their usefulness in the hands of clinical psychiatrists), and remain available under their original trade names or as generic or "me-too" formulations. Others may be substituted by substances with close pharmacological and therapeutic profiles (e.g., selective serotonin reuptake inhibitors and "dual" reuptake inhibitors). The development and marketing of these newer drugs was facilitated by the introduction of the concept of major depressive disorder (MDD) in the 1980s. MDD has repeatedly been criticized for its lack of validity, but was retained for its easier use in general clinical practice.

A number of older substances display such marked, consistent efficacy that their absence from guidelines or consensus initiatives did not discourage clinicians from continued prescribing to their patients. Unfortunately, many of those efficacious medications have vanished from Brazilian drugstore shelves over the past 20 years. Tranylcypromine and phenelzine (the most studied non-selective MAOIs), maprotiline (the only selective noradrenaline reuptake inhibitor), imipramine (the goldstandard, most effective antidepressant for severe "melancholic" depression), pimozide (particularly efficacious for Tourette syndrome), penfluridol (a long-acting oral antipsychotic which could be taken once a week), and lithium carbonate have been gone from our pharmacies either temporarily or for good. Only tranylcypromine and lithium have been reintroduced, after much protest by psychiatrists and patients.

Excuses are unclear, unjustified, and/or unconvincing. The cause is strictly economic: most proven drugs are now off-patent, have lost their share of the market to heavily promoted newer drugs, and became commercially uninteresting. Governments are unable to engage their limited pharmaceutical laboratories to assume the role of the private sector with the required standards. This creates a damaging vacuum. Many patients respond better or remit only under therapy with proven, old, cheap medicines. Their discontinuation may cause immediate relapse of serious disorders, and bring further crisis to a medical system already stressed by the COVID-19 pandemic. A feasible solution to the conflict between the demand for essential medicines, the legitimate interests of the pharmaceutical industry, and the limitations of the State in a democratic society must be urgently found.

\section{Disclosure}

The authors report no conflicts of interest.

\section{References}

1 Cade JF. Lithium salts in the treatment of psychotic excitement. Med J Aust. 1949;2:349-52.

2 Schou M, Juel-Nielsen N, Stromgren E, Voldby H. The treatment of manic psychoses by the administration of lithium salts. J Neurol Neurosurg Psychiatry. 1954;17:250-60.

3 Pereira VS, Hiroaki-Sato VA. A brief history of antidepressant drug development: from tricyclics to beyond ketamine. Acta Neuropsychiatr. 2018;30:307-22.

4 Kuhn R. The treatment of depressive states with G 22355 (imipramine hydrochloride). Am J Psychiatry. 1958;115:459-64.

5 Loomer HP, Saunders JC, Kline NS. A clinical and pharmacodynamic evaluation of iproniazid as a psychic energizer. Psychiatr Res Rep Am Psychiatr Assoc. 1957;8:129-41.

6 Kline NS. Clinical experience with iproniazid (Marsilid). J Clin Exp Psychopathol. 1958;19(2 Suppl. 1):72-8.

7 Delay J, Deniker P, Harl JM. [Therapeutic use in psychiatry of phenothiazine of central elective action (4560 RP)]. Ann Med Psychol (Paris). 1952;110:112-7.

8 López-Muñoz F, Alamo C, Cuenca E, Shen WW, Clervoy P, Rubio G. History of the discovery and clinical introduction of chlorpromazine. Ann Clin Psychiatry. 2005;17:113-35.

9 Ban TA. Fifty years chlorpromazine: a historical perspective. Neuropsychiatr Dis Treat. 2007;3:495-500.

10 Sani G, Perugi G, Tondo L. Treatment of bipolar disorder in a lifetime perspective: is lithium still the best choice? Clin Drug Investig. 2017;37:713-27.

11 Ferreira-Garcia R, da Rocha Freire RC, Appolinário JC, Levitan MN, Halkjær-Lassen RD, Bueno JR, et al. Tranylcypromine plus amitriptyline for electroconvulsive therapy-resistant depression: a longterm study. J Clin Psychopharmacol. 2018;38:502-4. 